Journal of Consumer Marketing

Emerald Journal of

Consumer Marketing

Consumer interpretation of brand prominence signals: insights for a broadened typology

\begin{tabular}{|r|l|}
\hline Journal: & Journal of Consumer Marketing \\
\hline Manuscript ID & JCM-11-2014-1226.R4 \\
\hline Manuscript Type: & Regular Paper \\
\hline Keywords: & $\begin{array}{l}\text { branding, brand prominence, consumer identity projects, impression } \\
\text { management, conspicuous consumption, consumer behavior }\end{array}$ \\
\hline
\end{tabular}

SCHOLARONE" 


\title{
Consumer Interpretation of Brand Prominence Signals: Insights for a Broadened Typology
}

\begin{abstract}
Purpose - Brand prominence describes the conspicuousness of a brand on a product. The purpose of the present research is to investigate the types of brand prominence variation.

Methodology - Utilizing an exploratory approach, 20 in-depth interviews were conducted where respondents created five outfits for anticipated social scenarios. The prominence of brands on these outfits were photographed, catalogued and qualitatively analyzed for thematic variation. Then, the brand prominence data points were quantitatively content analyzed.
\end{abstract}

Findings - The results from the qualitative analysis is an organizing framework describing three major types of brand prominence variation: brand visibility, brand frequency and brand distribution. In addition, heat maps were generated to visually display the prominence of brands distributed on the individual's body. Subsequent results from the quantitative content analysis revealed that brands on shoes and pants were most likely to display significant levels of prominence in relation to frequency and visibility dimensions. Significant differences across participant demographic groups were also found in terms of the brand visibility.

Practical Implications - This new information on brand prominence variation provides business brand managers with insight on how to measure and monitor their own levels of brand prominence displays. They, in turn, can engage in more strategic placement and prominence of their brands in the future production of fashionable clothes, shoes and accessories.

Originality - The conspicuous consumption literature has long been interested in studying how consumers display their brands. The current study demonstrates how consumer researchers can measure brand prominence variation, and therefore gain better insight on the consumer who engages in conspicuous consumption via brand prominence variation.

Keywords branding; brand prominence; consumer identity projects; impression management; conspicuous consumption; consumer behavior

Article Classification Research paper 


\section{Introduction}

Conspicuous consumption has been heavily documented in the academic literature, and it has been a topic of interdisciplinary interest by academics for decades. Veblen's (1899) The Theory of the Leisure Class remains a classic in supplying an analytical framework for studying this phenomenon in the social sciences. Recently, a new construct has been added to this field of study: brand prominence. This construct was first introduced by Han, Nunes and Dreze (2010), and is defined as the conspicuousness of a brand on a product. Brands that are more conspicuous are viewed as being more prominent because they are sending louder signals to others, and vice versa. Because of this, the consumer who engages in high levels of brand prominence behaviors is engaging in a louder form of conspicuous consumption. The extant literature on brand prominence only measures this construct in terms of a loudness or quietness continuum. The current research study aims to extend the brand prominence literature by providing additional ways to operationalize this construct. This will enable further investigations into brand prominence variation by other academic researchers as well as business practitioners.

An exploratory study design with a sequential data analysis was developed in order to better understand the consumer behaviors related to the phenomenon of brand prominence. Twenty in-depth interviews were conducted, and photographic methods were utilized to capture and document brand prominence variations. This visual data was first qualitatively analyzed via a content assessment (Step 1). Three thematic dimensions emerged from this analysis and are presented below as an organizing framework. Then, the researchers went back over this visual data and conducted a quantitative content analysis (Step 2). This process of analyzing the same dataset qualitatively and then quantitatively was implemented because it allows for a deeper understanding of complex cultural phenomena (Teddlie and Tashakkori, 2013, p. 156). The results from the content analysis revealed individual 
differences in relation to brand prominence variation. Overall, the aim of this paper is to examine the different types of brand prominence variation, and how these dimensions vary based on individual consumers.

\section{Literature Review \\ Consumer identity projects and conspicuous consumption}

An individual's identity is made up of two parts, the individual's evaluation of himself or herself which is called self-concept, and the individual's social identity which evaluates how others view him or her (Burns, 1979). Identity projects are a process of negotiation between the self and various social others. One technique utilized by individuals during times of negotiation is impression management (Goffman, 1959). During this process, the individual attempts to exert control over the perceptions others may have of him or her as he or she strives to develop congruence between self-perception and perception by others. Studying impression management via conspicuously consumed brands can provide researchers with insight on the identity process. In the marketing and consumer behavior literature, the impression management process is often referred to as consumer identity projects (Arnould and Thompson, 2005).

Veblen's (1899) The Theory of the Leisure Class is a seminal resource for researchers studying conspicuous consumption. Veblen analyzed the social distinctions generated among the classes of a society through the displayed conspicuousness of certain behaviors. Specifically, the conspicuous consumption of leisure and the conspicuous consumption of products are ways for individuals with a privileged status to communicate their higher social rank to others. Much of the contemporary academic literature picks up where Veblen left off by incorporating brands into the discussion of conspicuous consumption behaviors (Eastman and Liu, 2012). For example, Wang and Griskevicius (2014) found that although men use 
luxury brands as a way to attract potential romantic partners, women are more likely to use luxury brands as a way to deter potential romantic rivals. In what they call "mate guarding" (p. 835), women manage the threat of relationship poachers by showing how devoted their boyfriend/husband is through the displayed consumption of luxury brand clothing, handbags and other accessories. The woman is signaling that her relationship status is one of deep commitment. Kwak and Sojka (2010) found that Hispanic and Asian immigrants to the United States who strongly identify with their ethnic culture and those with higher household incomes are more likely to engage in conspicuous consumption. Therefore, it was important to these individuals to signal to themselves and to others the meanings attached to their social identities. Finally, Coskuner-Bali and Thompson (2013) found that consumer identity projects are important for both the signaling of one's identity to oneself as well as to others in their study of stay-at-home fathers.

\section{Brand prominence}

In 2010, Han, Nunes and Dreze revolutionized the conspicuous consumption literature by introducing the construct of brand prominence. They defined brand prominence as, "the conspicuousness of a brand's mark or logo on a product" (p. 15). In other words, a brand that would rate high on prominence means that the individual is engaging in a louder form of conspicuous consumption. This individual is prominently sending signals about his or her identity to others. In contrast, someone wearing a brand with low brand prominence is engaging in a much quieter version of conspicuous consumption. Or, they may not be engaging in conspicuous consumption at all. The introduction of the brand prominence construct generated a new perspective on consumer behaviors associated with conspicuous consumption. However, the authors only operationalized the brand prominence construct as merely a loud and quiet continuum of conspicuousness. This can be seen in the discussion of 
their exploratory studies, which established a negative linear relationship between brand prominence and price for luxury goods.

The intent of the current study is to further document and analyze consumer behaviors related to brand prominence. Here, the goal is to understand how consumers engage in varying levels of brand prominence. Therefore, the research questions for this study are the following: 1) what are the different types of brand prominence variation? and 2) how do brand prominence dimensions vary based on demographics?

\section{Methodology}

An exploratory study design was implemented, whereby a qualitative data analysis was completed in Step 1, and a quantitative data analysis was completed in Step 2. In addition, the use of photographs as data to document social phenomena is becoming increasingly more common in marketing and consumer research (Basil, 2011). Photographic methods were used in this study to capture and document brand prominence variations.

\section{Sampling}

A combination of purposive and snowball sampling methods was used to gain access to 20 interview participants. Purposive sampling is a technique to gather cultural complexity from a small pool of participants. In addition, snowball sampling is a means of gathering participants that were both known and unknown to the researcher before the interview took place. Men and women from a variety of ages and ethnicities were interviewed. Table I summarizes the demographics for the research participants. The average age of the participants was 23.6. These interviews took place in a capital city of the South central part of the United States during the spring season (March-May).

\section{[INSERT TABLE I HERE]}




\section{Protocol}

The interviews occurred in the participant's home, and each interview lasted about two hours. By observing consumers in a naturalistic setting rather than a laboratory, the researchers were able to obtain a clearer understanding of how consumers interact with the brands they consume in their everyday lives (Lincoln and Guba, 1985). Each respondent was asked to create five outfits from their current set of branded product possessions for the following social situations: 1) an outfit for a typical workday, 2) an outfit for going out with friends, 3) an outfit for an evening meal with one's family, 4) an outfit for date night with one's significant other and 5) their favorite outfit. Here is an excerpt from the interview protocol explaining the process:

"I am going to give you several scenarios, and based off of the items you currently own, I would like you to put together an outfit for each scenario. I don't want you to put the outfit on, just arrange the items together, and I would like to take a picture of the outfit. All of these scenarios are for when you leave your house, so I would like you to include everything you would take with you as you walk out the front door (cell phone, jacket, purse, sunglasses, etc.). Also, for each outfit I am going to write down the brands, and we will discuss the brands in the next section."

One-by-one, each outfit was gathered and assembled by the participant, and then it was documented by the interviewer. Once all five outfits had been created and recorded, the participant was then asked a series of questions about the importance of the brands associated with those outfits and why they fit that particular scenario ("Can you tell me what you think about this brand?"; "How would you describe this brand's personality?"; "Do you feel that this personality is similar to your own?"; "How would you summarize this brand using three adjectives?"). Finally, participants were asked to fill out a brief demographic survey, and then they were debriefed by the researcher.

Analysis

Like stated above, the data analysis methodology involved the sequential analysis of the same dataset via both qualitative and quantitative approaches. First, the visual data collected from 
the interviews were analyzed through thematic analysis and content assessment (Step 1).

Thematic codes on brand prominence variation emerged from this analysis and are presented below as an organizing framework. These findings answer the first research question. Next, based on the findings of Step 1, a set of hypotheses were advanced. Then, the same visual data from Step 1 were analyzed again from a quantitative standpoint, using a content analysis (Step 2). The results from Step 2 revealed variation in brand prominence consumer behaviors based on the hypotheses examined, and provide answers to research question 2 . The following two sections discuss this sequential analysis methodology in more detail.

\section{Step 1: Qualitative Analysis, Findings and Hypotheses Formulation}

Utilizing Weiss's (1994) methodology of coding, sorting, local integration and inclusive integration, several brand prominence themes inductively arose out of the photographic data. The three primary brand prominence variations found in Step 1 of the study are: 1) brand visibility, 2) brand frequency and 3) brand distribution. Each brand prominence theme will be presented, and a photographic data example will be displayed in order to illustrate the theme. In addition, each brand prominence variation contains several facet dimensions. Table II summarizes the results of Step 1.

\section{[INSERT TABLE II HERE]}

\section{Brand Visibility}

Brand visibility describes the extent that other individuals can perceive a conspicuous brand on a person or a product. The first facet of brand visibility describes whether or not a conspicuous brand is present. This is a present or absent dichotomy and will be referred to as brand visibility presence. The second facet of brand visibility describes the size of the brand in terms of its physical dimensions. Each conspicuous brand could be measured in terms of its height, width and square inch area. This construct will be called brand visibility size. The 
third facet of brand visibility is the clarity of the socially-visible brand. Some brands are clear and easy to see, while others are partially covered from view. These obstructions decrease the brand's visibility, and therefore brand prominence. This construct will be called brand visibility clarity.

In terms of brand visibility presence, prominent brands are either present on a product or they are not. Figure 1 displays all five outfits created by a single research participant. The two outfits in Figure 1(a) do not display any conspicuous brands, while the other three outfits each display one conspicuous brand. The outfit in Figure 1(b) displays the Franklin Covey brand on the handbag, the outfit in Figure 1(c) displays the Union Bay brand on the tongue of the shoes and the outfit in Figure 1(d) displays the Adidas brand on the back of the shoes. Therefore, the first two outfits do not include any prominent brands, while the other three outfits do include prominent brands. From day-to-day, consumers may fluctuate on whether or not they are wearing a prominent brand and engaging in conspicuous consumption. In addition, some consumers wear conspicuous brands, while others do not. It is important to note that some of the research participants in this study did not include a single prominent brand on any of their five outfits, while other participants displayed a prominent brand on each of their five outfits. The presence of conspicuous consumption is the focus of this study; however, it is important to note that not all products display a prominent brand.

\section{(INSERT FIGURE 1 HERE)}

Like stated above, brand visibility size describes the physical dimensions of a conspicuous brand. In Figure 2, two t-shirts demonstrate the concept of brand visibility size. The shirt in Figure 2(a) has a smaller Billabong brand conspicuously displayed compared to the Adidas brand conspicuously displayed on the shirt in Figure 2(b). In terms of physical dimensions, the Adidas brand is larger than the Billabong brand. Therefore, it can be argued 
that the Adidas brand is more prominent in terms of its size, and it is sending a louder signal to others.

\section{(INSERT FIGURE 2 HERE)}

Brand visibility clarity is a subjective estimation of how noticeable the conspicuous brand appears on a product. As one can see in Figure 3, the shirt in Figure 3(a) with the conspicuous Nike brand has a semi-transparent logo. The yellow and orange colors of the logo is similar to the yellow background of the shirt, and therefore does not visually contrast from it. The sweatshirt in Figure 3(b) displays a Puma brand conspicuously. The green background on this shirt contrasts heavily with the yellow brand and therefore allows a higher level of visual clarity to onlookers. One could argue that the sweatshirt on the right has a more prominent brand than the shirt on the left in terms of brand visibility clarity. Therefore, the Puma brand is louder than the Nike brand in this scenario.

\section{(INSERT FIGURE 3 HERE)}

\section{Brand Frequency}

The second major theme, brand frequency, describes the number of conspicuous brands. Brand frequency can be further broken down by the number of brands on the individual and on each product. For example, person A may be wearing one conspicuous brand, while person B may be wearing five conspicuous brands. This facet shows a variability of brand prominence on the individual in terms of frequency. In addition, a product may display more than one conspicuous brand. Therefore, the four facets of brand frequency are: individual unique brand frequency, individual gross brand frequency, product unique brand frequency and product gross brand frequency. As one can see, brand frequency can vary from one to infinity, but it cannot be zero because a conspicuous brand must first be present in order to count it. 
Figure 4 shows an example of individual unique brand frequency. These photos are from two outfits created by the same research participant, but for different social scenarios. The work outfit in Figure 4(a) displays one conspicuous brand: Dockers. The outfit for going out with friends in Figure 4(b) displays three conspicuous brands: Polo Ralph Lauren, Calvin Klein and Adidas. Since the outfit on the left displays only one unique brand, while the outfit on the right displays three unique brands, it can be determined that the outfit on the right has a higher individual unique frequency of conspicuous brands than the outfit on the left.

Therefore, the brand prominence is higher for the outfit on the right in comparison to the outfit on the left.

\section{(INSERT FIGURE 4 HERE)}

Figure 5 displays two outfits created by another research participant and is an example of individual gross brand frequency. The favorite outfit in Figure 5(a) displays one conspicuous brand: Fossil. The work outfit in Figure 5(b) displays three conspicuous brands; however, all three are the Fossil brand. This outfit would have a unique brand frequency of one, but a gross brand frequency of three. Gross brand frequency counts each conspicuous brand displayed on an outfit, while unique brand frequency counts each distinct conspicuous brand. Again, the outfit on the right displays higher levels of brand prominence.

\section{(INSERT FIGURE 5 HERE)}

Product unique brand frequency describes the number of unique conspicuous brands on each product. In Figure 6, one can see that the shirt in Figure 6(a) displays one sociallyvisible brand, Armani Exchange, and the shirt in Figure 6(b) displays three unique brands: NBA (National Basketball Association), Los Angeles Lakers and Nike. The shirt on the right has a higher frequency of unique brands compared to the shirt on the left.

(INSERT FIGURE 6 HERE) 
Product gross brand frequency describes the total number of conspicuous brands on each product. Figure 7 displays two Armani Exchange shirts. The shirt in Figure 7(a) displays the Armani Exchange logo one time, and it therefore has a gross brand frequency count of one. The shirt in Figure 7(b) displays the words "Armani Exchange" six times. This shirt has a gross brand frequency of six. It is important to point out that both shirts display the exact same conspicuous brand, and therefore have identical unique brand frequencies of one. But, the shirt on the right has a higher gross brand frequency than the shirt on the left, and has higher levels of brand prominence.

\section{(INSERT FIGURE 7 HERE)}

\section{Brand Distribution}

Finally, brand distribution describes the location of the conspicuous brand on the individual and on each product. Therefore, the two facets of brand distribution are: individual brand distribution and product brand distribution. Figure 8 displays a single outfit from one of the research participants. On that outfit, one can see three socially-visible brands: Express, Hollister and Puma. The Express brand is located twice on the individual's torso, the Hollister brand is located on the individual's legs and the Puma brand is located on the individual's feet. Each brand is distributed on a separate location of the individual's body, and varies in terms of its brand prominence. When an individual is walking down the street, other individuals will be able to see certain brands and not others, depending on their perspective. Arguably, conspicuous brands that are more at eye-level (i.e., on the head, torso) will have higher brand prominence than others (i.e., legs and feet). In addition, conspicuous brands on one's front versus back will also fluctuate in terms of brand prominence depending on the spatial relationship the individual has with others. Others walking behind the individual will see the brands on the individual's back more easily than the ones on the individual's front, and vice versa. 
(INSERT FIGURE 8 HERE)

For product brand distribution, Figure 9 exhibits four shirts. Each shirt has a single conspicuous brand, and each shirt has this brand in a different location. The shirt in Figure 9(a) shows the Tommy Hilfiger brand on the upper-central part of the shirt. The shirt in Figure 9(b) shows the Antigua brand on the shirt's right sleeve. The shirt in Figure 9(c) displays the Izod brand on the shirt's left sleeve. Finally, the sweatshirt in Figure 9(d) displays the Russell brand on the lower-left part of the shirt. From these four examples, one can begin to see the various locations it is possible to display a conspicuous brand on a single product, which in turn impacts how visible that brand is to others, and therefore that brand's prominence.

\section{(INSERT FIGURE 9 HERE)}

Since individual and product brand distribution was captured and analyzed visually rather than numerically, a hypothesis cannot be tested statistically for these two variables. Instead, an exploratory analysis was used via heat maps to gain some preliminary insights. Heat map distributions were created by utilizing Qualtrics software. One-by-one, each photographed conspicuous brand was recorded using the click of a mouse on a representative grid of a human body-with both a front and back image. When a bunch of mouse clicks start to cluster together, the grid displays a level of "heat." Therefore, the heated areas on the grid show concentrations of brand prominence. Figure 10 shows the distribution of prominent brands from all 20 research participants on an individual's body. On the left hand side, one can see that conspicuous brands are often worn on the front of one's body, the sides of one's feet, near one's navel, in one's hands, or in the upper left of the individual's torso (upper right from another person's perspective). Meanwhile, one the back of the body, conspicuous brands are often worn on the upper right of the individual's waist and on the back of one's 
feet. It is clear from these heat maps that the "hottest" part of one's body to display conspicuous brands tends to be on one's feet.

\section{[INSERT FIGURE 10 HERE]}

In summary of Step 1, brand visibility presence, size and clarity may vary by consumer, indicating preferences for brand visibility. But they may also vary per outfit of the same consumer, indicating that consumers may choose the degree of brand visibility presence per outfit depending on the social situation. Based on evolutionary psychology literature, and sexual selection principles-which focuses on enhancing traits that enable mate acquisition (Moorad, 2013; Schmitt and Rohde, 2013)-younger or single or male consumers may be more likely to engage in behaviors aimed at attracting the opposite sex, and therefore engage in louder brand prominence behaviors, than older or married or female consumers.

Differences may also exist for brand visibility based on education, ethnicity and household income, although a specific hypothesis cannot be advanced at this stage due to the lack of prior literature. Given that only brand visibility presence can be objectively assessed via a quantitative methodology given that size and clarity are subjective in nature and dependent on other individual factors, a hypothesis is advanced only for this dimension of brand visibility. Thus:

H1: Brand visibility presence will be higher for a) younger consumers than older consumers, b) single consumers than married consumers and c) male consumers than female consumers.

In addition, depending on the occasion, consumers may choose outfits with varying degrees of brand visibility presence. For example, when consumers go out for a date night with one's significant other, they may wear clothes with a greater degree of brand visibility presence than at work (Sundie et al., 2011). Therefore:

H2: A consumer's clothes brand visibility presence will vary by occasion (i.e. per outfit). 
Similar, to the rational for $\mathrm{H} 1$ on brand visibility presence and prior literature on evolutionary psychology and sexual selection, it is hypothesized that younger, or single, or male consumers will have a greater number of individual unique brand frequency and individual gross brand frequency. Differences based on education, ethnicity and household income are not hypothesized but will be explored.

H3: Individual unique brand frequency will be higher for a) younger consumers than older consumers, b) single consumers than married consumers and c) male consumers than female consumers.

H4: Individual gross brand frequency will be higher for a) younger consumers than older consumers, b) single consumers than married consumers and c) male consumers than female consumers.

Product unique brand frequency and product gross brand frequency may also vary per article of clothing. Some clothes are more likely to feature brand logos and names than others (Berger, 2010):

H5: a) Product unique brand frequency and b) product gross brand frequency will vary by article of clothing.

In Step 2, the photographic data from the interviews in Step 1 were quantitatively content analyzed in order to measure and explore themes of brand prominence.

\section{Step 2: Quantitative Analysis and Findings}

Scholars have generally acknowledged that content analysis is a viable research method for understanding various aspects of content, and is especially helpful in exploring an underexplored phenomenon in a constructive manner, which is the focus of this study on brand prominence variation. The hypotheses advanced during Step 1 enabled the testing of differences in brand prominence variation related to brand visibility presence (H1 and $\mathrm{H} 2)$, individual unique and gross brand frequency (H3 and $\mathrm{H} 4)$ and product unique and gross brand frequency (H5). 


\section{Coding procedure}

With 20 participants interviewed, and five outfits put together by each participant, the result was a sample of 100 cases. Both authors content analyzed all 100 cases separately before resolving differences. The content analysis process began by first coding the type of clothing items included in each outfit (i.e., hat, sunglasses, jewelry, shirt and jacket). Coders then counted whether or not a brand was visible on the outfit (brand visibility presence). Efforts were made to record the small, medium and large size (brand visibility size) in addition to the starkness (brand visibility clarity) by using coder quartiles ( $0 \%$ clear; $25 \%$ clear; $50 \%$ clear, $100 \%$ clear). However, given their subjective nature these evaluations were deemed not appropriate for a proper content analysis, which is why hypotheses were not advanced for these evaluations of brand visibility. Next, the number of unique visible brands (individual unique brand frequency) and the total number of visible brands (individual gross brand frequency) on each outfit per participant were coded. Coders also counted the number of unique visible brands and the total number of visible brands on each article of clothing for each outfit per participant (product unique brand frequency and product gross brand frequency).

Intercoder reliabilities were computed to ensure the reliability of the coding process. Table III shows the intercoder reliability measures used in this study for the aforementioned categories, except brand distribution which was analyzed via heat maps and is discussed above. Four intercoder reliability measures were employed: percentage agreement, Scott's pi, Cohen's kappa and Krippendorff's alpha. Based on Neuendorf (2002), intercoder reliabilities above .60 are acceptable, but anything below it should be discarded from the analysis. All the items coded had acceptable intercoder reliabilities, except product gross brand frequency jacket product gross brand frequency electronic. After differences were resolved, the items that had acceptable intercoder reliabilities were further analyzed using SPSS. Frequencies 
and percentages were calculated and those differences were examined via chi-squares and ANOVAs tests, to explore individual differences in brand prominence variations.

\section{[INSERT TABLE III HERE]}

\section{Brand visibility}

Like stated above, brand visibility describes the extent that other individuals can perceive a conspicuous brand on a product. Based on the content analysis results, $64 \%$ of all outfits had a conspicuous brand on a product. Significant differences did exist per participant $\left(\chi_{(19)}^{2}=42.70, p<.01\right)$ as expected, but not per outfit $\left(\mathrm{F}_{(1,98)}=2.64, \mathrm{p}>.05\right)$, which may indicate preferences of consumers on brand visibility, but not differences per occasion, respectively. Thus, H1 was subsequently explored further in terms of the source of variation for brand visibility presence per consumer, while $\mathrm{H} 2$ was found not to be supported. In particular, in terms of $\mathrm{H} 1$, when comparing younger participants with older participants based on a mean split $\left(\chi_{(1)}^{2}=.13, \mathrm{p}>.05\right)$ no differences emerged in brand visibility presence, but when the continuous measure of age was used differences due to age were significant $\left(\mathrm{F}_{(14,85)}=3.35\right.$, $\mathrm{p}<.01)$. Consumers ages 26 to 34 had more brand visibility presence than other ages. No differences were also found between single and married participants $\left(\chi_{(1)}^{2}=3.83, p>.05\right)$. Thus, H1a and H1b were not supported. However, male participants were found to be more likely to have brand visibility presence on their outfits compared to women $\left(\chi_{(1)}^{2}=18.24\right.$, $\mathrm{p}<.01$; Males with brand visibility presence: 39 out of 45 ; Females with brand visibility presence: 25 out of 55), thus, supporting H1c.

Differences in brand visibility presence were also tested for education $\left(\mathrm{F}_{(4,95)}=3.27\right.$, $\mathrm{p}<.05)$, ethnicity $\left(\mathrm{F}_{(3,96)}=1.00, \mathrm{p}>.05\right)$ and household income $\left(\mathrm{F}_{(3,96)}=2.27, \mathrm{p}>.05\right)$. Statistically significant differences were only found in brand visibility presence based on education, with participants who had some college $(\mathrm{M}=.84, \mathrm{SD}=.37)$ having the greatest brand visibility 
presence, followed by those who finished high school $(\mathrm{M}=.80, \mathrm{SD}=.44)$ and graduates $(\mathrm{M}=.80, \mathrm{SD}=.41)$, than other education levels. In summary, brand visibility presence varies by gender, age and education level.

\section{Brand frequency}

Brand frequency describes the number of conspicuous brands on a product. Means and standard deviations were used to calculate the mean individual unique and individual gross brand frequencies. Each participant had on average more than one unique visible brand on his or her outfit $(\mathrm{M}=1.35 ; \mathrm{SD}=1.37)$, while the maximum number of unique visible brands on a participant was five (ranging from 1 to 5). In addition, each participant had on average more than 3 gross visible brands on his or her outfit $(M=3.16 ; \mathrm{SD}=4.55)$. However, results showed that there was a lot of variation in terms of the individual gross brand frequency, as each participant's individual gross brand frequency, ranged from 1 to 32 visible brands. ANOVAs were also used to examine differences in individual unique and gross brand frequencies among demographic groups

Using a dichotomous age division between younger and older participants based on a mean split, no significant differences were found for individual unique and gross brand frequencies $\left(\mathrm{F}_{(1,98)}=.01, \mathrm{p}>.05\right.$; and $\mathrm{F}_{(1,98)}=.40, \mathrm{p}>.05$, respectively). However, using a continuous measure of age, individual unique and gross brand frequencies did differ by age $\left(\mathrm{F}_{(14,85)}=8.04, \mathrm{p}<.01 ;\right.$ and $\mathrm{F}_{(14,85)}=3.22, \mathrm{p}<.01$, respectively) however, without a clear pattern emerging. Therefore, findings do not support $\mathrm{H} 3 \mathrm{a}$ and $\mathrm{H} 4 \mathrm{a}$ respectively, although age differences may exist. No differences were also found between single and married participants in terms of their individual unique and gross brand frequency $\left(\mathrm{F}_{(1,98)}=3.25\right.$, $\mathrm{p}>.05$; and $\mathrm{F}_{(1,98)}=.31, \mathrm{p}>.05$, respectively) therefore $\mathrm{H} 3 \mathrm{~b}$ and $\mathrm{H} 4 \mathrm{~b}$ were not supported. Females had significantly less individual unique (maximum 3 individual unique brands, while men had a maximum 5 individual unique brands) and individual gross (maximum 12 
individual gross brands, while men had a maximum 32 individual gross brands) brand frequencies than men $\left(\mathrm{F}_{(1,98)}=48.99, \mathrm{p}<.01, \mathrm{M}_{\text {males }}=2.22, \mathrm{M}_{\text {females }}=.63\right.$; and $\mathrm{F}_{(1,98)}=18.52$, $\mathrm{p}<.01, \mathrm{M}_{\text {males }}=5.15, \mathrm{M}_{\text {females }}=1.52$; respectively ), thus supporting $\mathrm{H} 3 \mathrm{c}$ and $\mathrm{H} 4 \mathrm{c}$, respectively. Even though specific hypotheses were not advanced, significant differences in individual unique brand frequencies were also found by ethnicity $\left(\mathrm{F}_{(3,96)}=3.95, \mathrm{p}<.05\right)$, education $\left(\mathrm{F}_{(4,95)}=4.76, \mathrm{p}<.01\right)$ and household income $\left.\mathrm{F}_{(3,96)}=3,90, \mathrm{p}<.05\right)$, but not for individual gross brand frequencies (Ethnicity: $\mathrm{F}_{(3,96)}=1.40, \mathrm{p}>.05$; Education: $\mathrm{F}_{(4,95)}=2.27$, $\mathrm{p}>.05$; Household Income: $\left.\mathrm{F}_{(3,96)}=1.84, \mathrm{p}>.05\right)$. Asian Americans had significantly higher individual unique brand frequencies, followed by African Americans and Caucasians. Hispanic Americans were the ones with the least number of individual unique brand frequencies. Those participants with some undergraduate credit and postgraduate degrees had higher individual unique brand frequencies than those with undergraduate degrees, a high school degree and those who had finished some postgraduate credit. Interestingly, the participants with lower than $\$ 10,000$ household income had higher individual unique brand frequencies, than participants with higher income levels.

Next, percentages were calculated for each article of clothing to identify the number of product unique and gross brand frequencies. Results can be seen in Table IV. The maximum number of product unique visible brands was two. Pants were the article of clothing most likely to have at least one product unique visible brand, while hats and dresses had none. Two percent of the outfits including shoes had two unique visible brands. Shoes, followed by pants were the articles of clothing most likely to have three or more product gross visible brands, while jackets, shirts and sunglasses were more likely to have two. Next, these frequencies calculated for the first product unique brand frequencies and first product gross brand frequencies per article of clothing-as depicted in Table IV-were used as the data to compare differences between articles of clothing, statistically for H5 (although limitations 
of this approach should be noted as some articles of clothing such as shoes, had 2 product unique and 3 or more product gross brand frequencies which could not be taken into account). Findings illustrated that there were no significant differences in terms of the first product unique and gross brand frequencies in terms of articles of clothing $\left(\mathrm{F}_{(8,1)}=.45, \mathrm{p}>.05\right.$ and $\mathrm{F}_{(6,3)}=.41, \mathrm{p}>.05$, respectively).

\section{[INSERT TABLE IV HERE]}

In summary, for brand frequency significant differences existed for individual unique brand frequency among participants in different age, gender, income, education and ethnic groups, and significant differences existed for individual gross brand frequency among participants in different age, gender and marital status groups. Lastly, Table V illustrates the detailed results of the ANOVAS that had significant results.

[INSERT TABLE V HERE]

\section{Discussion}

One of the most interesting outcomes of this exploratory study is the application of both inductive and deductive logic to the same social phenomenon. This aim of this study was to document the variations in brand prominence. The three themes of brand visibility, brand frequency and brand distribution inductively arose out of the data from Step 1. The organizing framework presented in Step 1 provides future researchers with a starting point to operationalize and analyzes the brand prominence construct.

In addition, the results of the content analysis in Step 2 showed that brand prominence variations do occur among individual consumers. As discussed above, shoes play an important role in this process. Conspicuous brands are the most common on this item, and it is the most dominant item in an individual's outfit. Given that about two-thirds of all the outfits captured for this study contained a conspicuous brand, and that on average each 
participant included more than one conspicuous brand in any given outfit, there are important implications for consumer researchers and for marketing and advertising practitioners.

For researchers, the medium of shoes for identity signaling is a new discovery. In the literature, the products that are typically the focus of consumer identity projects are either clothes or the accessories of sunglasses and purses (Berger, 2010). As shown here, shoes are another vehicle consumers utilize in order to signal aspects of their identity to others. In many ways shoes are an integral part of a consumer's outfit due to its functional benefits and societal norms. In addition, shoes are articles of clothing that can be worn with multiple outfits thus increasing the likelihood of exposing others to the brand signal due to a greater frequency of usage per individual. The study of how consumers incorporate the prominent brands on their shoes should be further explored.

\section{Managerial implications}

The results of this research study produced several managerial implications as well. Marketing practitioners play a huge role in brand prominence variation. They are the ones who create and generate these brands that consumers utilize for the conspicuous consumption identity process. They are the ones who determine the loudness and quietness of the brand on the product: whether or not the brand will be conspicuous, how big it will be, how many times it will appear on the article of clothing, which articles of clothing, etc. These decisions by brand managers supply their consumers with an array of options to choose from, which in turn impacts consumers' decisions on which products and which brands to purchase.

Signaling via brands is an important part of interpersonal communications and identity negotiations for some consumers. Therefore, identifying the needs and wants of consumers in terms of brand prominence would be important for marketing practitioners to understand.

This is especially true for brand managers, product designers and retail display managers. By conducting market research and measuring consumer preferences for variables 
such as individual gross brand frequency and brand visibility presence, marketing practitioners may better understand the levels of brand prominence that their target market prefers. They, in turn, can make better-informed strategic decisions on brand prominence dimensions to fit their consumers' needs, which in turn should produce higher levels of consumer-brand attachment, and ultimately consumer loyalty towards their brand. Plus, establishing measured brand prominence benchmarks will enable for more effective brand management. This new construct of brand prominence could open up a whole new discussion between suppliers and consumers via marketing research. A better understanding of brand prominence variation gives marketing practitioners a better understanding on how consumers are relating to their brands and products.

Again, the uncovering of the prevalence of brand prominence variation on shoes is a new discovery. Therefore, shoe manufacturers may have missed an opportunity to engage their consumers. By offering more variation of brand prominence, a firm might see an uptick in consumer interest in their product. One company that has obviously caught on to this trend is Nike. For decades, they have come out with new styles of shoes displaying variations of brand prominence for the Nike logo. However, there are a wide variety of other shoe manufacturers who could more intentionally apply these variations to their product. Luxury shoe brands in particular could benefit through more intentional use of brand prominence variations.

Clothing suppliers and retailors may also find this information on brand prominence variation especially useful. They could either be helping or hurting their business by including clothing and accessory items that show conspicuous brands according to their target market's preferences. Perhaps shirts with conspicuous brands on the upper torso are selling better than shirts with the brands on the lower torso. Perhaps shirts with a single logo are selling better than shirts with three logos. By investigating and understanding their target 
market's needs and wants in these categories, they could aid in the overall profitability of their given company. Brand managers for these companies should be conducting focus groups and surveys in order to understand their target market's preferences for brand prominence variations with their assortment of products. Then, by responding to those preferences, the company will be creating new products that fall in line with the needs of their consumer base.

In addition, the preliminary demographic differences in brand prominence variation behaviors hold implications for marketing and advertising practitioners. One of the most interesting findings of this study was the phenomenon of the male participants' inclination to include sunglasses and electronic devices in their outfits, while none of the female participants included these items. Men may view these items are more expressive elements of their identity than women. They may view them as a more appropriate signaling medium. Of course, many of the female participants included purses and jewelry in their outfits, while none of the male participants included these items. Therefore, sunglasses and electronic devices might represent a "male purse" or "male jewelry" in the consumer identity project process. Overall, the importance of demographics as an antecedent to the signaling process also needs to be taken more into consideration by both practitioners and scholars.

Brand visibility was analyzed in this study, and differences were observed between participants which may indicate that consumers have preferences on brand visibility. This is important especially in a marketing communications and advertising context as there needs to be congruent in terms of the preferences of the target audience on brand visibility and the brands visibility on the message itself targeted towards them. Interestingly, this study found that men have a greater preference for brand visibility than women, which is another finding that underlines the importance of demographics related to the signaling process. The operationalization of size and clarity of the brand visibility was not defined to a great enough 
extent to overcome intercoder reliability issues in this study. Future studies could explore ways to measure the physical size and clarity in a more objective manner.

Finally, brand distribution could also benefit from further operationalization and measurement rigor. This study was not able to explore whether or not significant differences existed in brand distribution by participant and outfit, however this study illustrated that brands may be placed in body parts that might increase the likelihood of signaling to others. Future studies could examine how advertisements can take advantage of brand distributions on articles of clothing depicted in advertisements and how it impacts purchase behavior.

\section{Conclusion}

Conspicuous consumption has been a topic of interest for consumer researchers for over a century. The recent introduction of the construct of brand prominence has shifted the discussion of this topic in that it gives researchers an additional avenue of exploration into this cultural phenomenon. The newly minted construct of brand prominence allows researchers to study the conspicuousness of brands on products. The current study was conducted to further the understanding of brand prominence variation. Twenty interviews were conducted, where participants created five outfits that were photographed, catalogued and content assessed and then content analyzed. The results of this exploratory study generated some new dimensions that can be used by other researchers to study this phenomenon. Step 1 uncovered the themes of brand visibility, brand frequency and brand distribution. Results from Step 2 showed that over half of the outfits created by participants contained at least one conspicuous, prominent brand. Plus, individual preferences of brand prominence variation were uncovered. In addition, shoes were an article of one's outfit where brand prominence was high, which is not an outcome that has been discussed in the conspicuous consumption literature before. Overall, this paper supplies insight on brand prominence variation and extends the conspicuous consumption literature. 


\section{References}

Arnould, E. J. and Thompson, C. J. (2005), “Consumer culture theory (CCT): Twenty years of research", Journal of Consumer Research, Vol. 31 No. 4, pp. 868-882.

Basil, M. (2011), "Use of photography and video in observational research", Qualitative Market Research, Vol. 14 No. 3, pp. 246-257.

Berger, J. (2010), “Subtle signals of inconspicuous consumption”, Journal of Consumer Research, Vol. 37 No. 4, pp. 555-569.

Burns, R. B. (1979), The Self-concept: Theory, Measurement, Development and Behavior, Longman, New York: NY.

Coskuner-Bali, G. and Thompson, C. J. (2013), “The status costs of subordinate cultural capital: At-home fathers' collective pursuit of cultural legitimacy through capitalizing consumption practices”, Journal of Consumer Marketing, Vol. 40 No. June, pp. 1941.

Eastman, J. K. and Liu, J. (2012), “The impact of generational cohorts on status consumption: an exploratory look at generational cohort and demographics on status consumption", Journal of Consumer Marketing, Vol. 29 No. 2, pp. 93-102.

Goffman, E. (1959), The Presentation of Self in the Everyday Life, Doubleday and Company, Inc., Garden City, NY.

Han, Y. J., Nunes, J. C. and Dreze, X. (2010), “Signaling status with luxury goods: the role of brand prominence", Journal of Marketing, Vol. 74 No. 4, pp. 15-30.

Kwak, L. E. and Sojka, J. Z. (2010), “If they could see me now: immigrants' use of prestige brand to convey status", Journal of Consumer Marketing, Vol. 27 No. 4, pp. 371-380.

Lincoln, Y. S. and Guba, E. G. (1985) Naturalistic Inquiry, Sage, Newbury Park, CA. 
Moorad, J. A. (2013), "Multi-level sexual selection: individual and family-level selection for mating success in a historical human population", Evolution, Vol. 67 No. 6, pp. 16351648.

Neuendorf, K. A. (2002), The Content Analysis Guidebook, Sage, Thousand Oaks, CA.

Schmitt, D. P. and Rohde, P. A. (2013), “The human polygyny index and its ecological correlates: testing sexual selection and life history theory at the cross-national level”, Social Science Quarterly, Vol. 94 No. 4, pp. 1159-1184.

Sundie, J. M., Kenrick, D. T., Griskevicius, V., Tybur, J. M., Vohs, K. D. and Beal, D. J. (2011), "Peacocks, Porsches and Thorstein Veblen: conspicuous consumption as a sexual signaling system", Journal of Personality and Social Psychology, Vol. 100 No. 4, pp. 664-680.

Teddlie, C. and Tashakkori, A. (2013), "Mixed methods research: Contemporary issues in an emerging field”, in Denzin, N. K. and Lincoln, Y. S. (Eds.). Strategies of Qualitative Inquiry, Sage Publications, Thousand Oaks, CA, pp. 135-168.

Veblen, T. (1899) The Theory of the Leisure Class, Dover, Mineola, NY.

Wang, Y. and Griskevicius, V. (2014), “Conspicuous consumption, relationships and rivals: Women's luxury product as a signal to other women", Journal of Consumer Research, Vol. 40 No. Feb., pp. 834-854.

Weiss, R. S. (1994) Learning from Strangers: The Art and Method of Qualitative Interview Studies, The Free Press, New York, NY. 
Table I Informant demographic information.

\begin{tabular}{|c|c|c|c|c|c|}
\hline$\#$ & Age & Sex & Ethnicity & Education & $\begin{array}{l}\text { Marital } \\
\text { status }\end{array}$ \\
\hline 1 & 19 & Female & Caucasian & Some undergraduate credit & Single \\
\hline 2 & 21 & Female & Hispanic & Some undergraduate credit & Single \\
\hline 3 & 24 & Female & Caucasian & Some postgraduate credit & Single \\
\hline 4 & 24 & Female & African American & Some postgraduate credit & Single \\
\hline 5 & 25 & Female & Caucasian & Undergraduate degree & Single \\
\hline 6 & 25 & Female & Hispanic & Some postgraduate credit & Single \\
\hline 7 & 28 & Female & Caucasian & Some postgraduate credit & Married \\
\hline 8 & 28 & Female & Caucasian & Some postgraduate credit & Married \\
\hline 9 & 28 & Female & Caucasian & Undergraduate degree & Married \\
\hline 10 & 42 & Female & Caucasian & Some undergraduate credit & Married \\
\hline 11 & 51 & Female & Caucasian & Undergraduate degree & Married \\
\hline 12 & 18 & Male & Caucasian & Some undergraduate credit & Single \\
\hline 13 & 19 & Male & Asian American & Some undergraduate credit & Single \\
\hline 14 & 26 & Male & $\begin{array}{l}\text { Caucasian, } \\
\text { Hispanic, and } \\
\text { Native American }\end{array}$ & Some postgraduate credit & Single \\
\hline 15 & 27 & Male & Caucasian & Undergraduate degree & Single \\
\hline 16 & 29 & Male & African American & Postgraduate degree & Single \\
\hline 17 & 32 & Male & African American & Postgraduate degree & Married \\
\hline 18 & 34 & Male & African American & Postgraduate degree & Married \\
\hline 19 & 36 & Male & Caucasian & Some postgraduate credit & Single \\
\hline 20 & 55 & Male & Caucasian & High school degree & Married \\
\hline
\end{tabular}


Table II Brand prominence variation organizing framework.

\begin{tabular}{|c|c|c|c|}
\hline Variation & Definition & Dimension & Operationalization \\
\hline \multirow[t]{3}{*}{ Brand visibility } & the extent that other & Presence & Present or absent \\
\hline & individuals can perceive & Size & Height and width \\
\hline & $\begin{array}{l}\text { a conspicuous brand on a } \\
\text { person or a product }\end{array}$ & Clarity & $0 \%$ to $100 \%$ \\
\hline \multirow[t]{4}{*}{ Brand frequency } & the number of & Individual unique & 1 to infinity \\
\hline & conspicuous brands & Individual gross & 1 to infinity \\
\hline & & Product unique & 1 to infinity \\
\hline & & Product gross & 1 to infinity \\
\hline \multirow[t]{2}{*}{ Brand distribution } & the location of the & Individual & Location on body \\
\hline & $\begin{array}{l}\text { conspicuous brand on the } \\
\text { individual and on each } \\
\text { product }\end{array}$ & Product & Location on product \\
\hline
\end{tabular}


Table III Intercoder reliability measures.

\begin{tabular}{|c|c|c|c|c|}
\hline Variable Name & $\begin{array}{l}\text { Percent } \\
\text { Agreement }\end{array}$ & Scott's Pi & $\begin{array}{l}\text { Cohen's } \\
\text { Kappa }\end{array}$ & $\begin{array}{l}\text { Krippendorff's } \\
\text { Alpha }\end{array}$ \\
\hline \multicolumn{5}{|l|}{ Article of Clothing } \\
\hline Hat & 100 & 1 & 1 & 1 \\
\hline Sunglasses & 100 & 1 & 1 & 1 \\
\hline Jewellery & 95 & 0.87 & 0.87 & 0.87 \\
\hline Shirt & 92 & 0.70 & 0.70 & 0.70 \\
\hline Jacket & 88 & 0.73 & 0.73 & 0.73 \\
\hline Trousers & 99 & 0.97 & 0.97 & 0.97 \\
\hline Dress & 96 & 0.86 & 0.86 & 0.86 \\
\hline Shoes & 100 & 1 & 1 & 1 \\
\hline Purse & 99 & 0.97 & 0.97 & 0.97 \\
\hline Electronic & 100 & 1 & 1 & 1 \\
\hline \multicolumn{5}{|c|}{ Individual Unique Brand Frequency (IUBF) } \\
\hline IUBF & 95 & 0.93 & 0.93 & 0.93 \\
\hline \multicolumn{5}{|c|}{ Individual Gross Brand Frequency (IGBF) } \\
\hline IGBF & 69 & 0.62 & 0.62 & 0.62 \\
\hline \multicolumn{5}{|c|}{ Product Unique Brand Frequency (PUBF) } \\
\hline PUBF Hat & 100 & 1 & 1 & 1 \\
\hline PUBF Sunglasses & 100 & 1 & 1 & 1 \\
\hline PUBF Jewellery & 98 & -0.01 & $\mathrm{n} / \mathrm{a}$ & -0.01 \\
\hline PUBF Shirt & 98 & 0.94 & 0.94 & 0.94 \\
\hline PUBF Jacket & 95 & 0.68 & 0.68 & 0.68 \\
\hline PUBF Trousers & 99 & 0.98 & 0.98 & 0.98 \\
\hline PUBF Dress & 100 & 1 & 1 & 1 \\
\hline PUBF Shoes & 98 & 0.95 & 0.95 & 0.95 \\
\hline PUBF Purse & 100 & 1 & 1 & 1 \\
\hline PUBF Electronic & 100 & 1 & 1 & 1 \\
\hline \multicolumn{5}{|c|}{ Product Gross Brand Frequency (PGBF) } \\
\hline PGBF Hat & 100 & 1 & 1 & 1 \\
\hline PGBF Sunglasses & 100 & 1 & 1 & 1 \\
\hline PGBF Jewellery & 98 & -0.01 & $\mathrm{n} / \mathrm{a}$ & -0.01 \\
\hline PGBF Shirt & 96 & 0.88 & 0.88 & 0.88 \\
\hline PGBF Jacket & 93 & 0.53 & 0.53 & 0.53 \\
\hline PGBF Trousers & 85 & 0.75 & 0.75 & 0.75 \\
\hline PGBF Dress & 100 & 1 & 1 & 1 \\
\hline PGBF Shoes & 89 & 0.79 & 0.79 & 0.79 \\
\hline PGBF Purse & 98 & 0.91 & 0.91 & 0.91 \\
\hline PGBF Electronic & 95 & 0.56 & 0.57 & 0.56 \\
\hline \multicolumn{5}{|l|}{ Brand Visibility } \\
\hline Brand Visibility & 100 & 1 & 1 & 1 \\
\hline
\end{tabular}


Table IV Product unique and gross brand frequencies.

\begin{tabular}{llllll}
\hline $\begin{array}{l}\text { Article of } \\
\text { Clothing }\end{array}$ & \multicolumn{2}{l}{$\begin{array}{l}\text { Product Unique } \\
\text { Brand Frequency }\end{array}$} & $\begin{array}{l}\text { Product Gross } \\
\text { Brand Frequency }\end{array}$ \\
\hline & $\begin{array}{l}\text { 1 product } \\
\text { unique }\end{array}$ & $\begin{array}{l}2 \text { product } \\
\text { unique }\end{array}$ & $\begin{array}{l}\text { 1 product } \\
\text { gross }\end{array}$ & $\begin{array}{l}\text { 2 product } \\
\text { gross }\end{array}$ & $\begin{array}{l}\text { 3 or more } \\
\text { product } \\
\text { gross }\end{array}$ \\
\hline Hat & $0 \%$ & -- & $0 \%$ & -- & -- \\
Sunglasses & $1 \%$ & -- & $0 \%$ & $1 \%$ & -- \\
Jewellery & $2 \%$ & -- & $2 \%$ & -- & -- \\
Shirt & $23 \%$ & -- & $21 \%$ & $2 \%$ & -- \\
Jacket & $11 \%$ & -- & $10 \%$ & $1 \%$ & -- \\
Trousers & $44 \%$ & -- & $25 \%$ & $8 \%$ & $11 \%$ \\
Dress & $0 \%$ & -- & $0 \%$ & -- & -- \\
Shoes & $31 \%$ & $2 \%$ & $1 \%$ & $12 \%$ & $20 \%$ \\
Purse & $12 \%$ & -- & $1 \%$ & -- & -- \\
Electronic & $6 \%$ & -- & $6 \%$ & -- & -- \\
\hline
\end{tabular}


Table V ANOVAs for hypotheses with significant results.

\begin{tabular}{llccccc}
\hline Hypothesis & Source & $\begin{array}{c}\text { Sum of } \\
\text { Squares }\end{array}$ & df & $\begin{array}{c}\text { Mean } \\
\text { Square }\end{array}$ & F & Sig. \\
\hline H1a & Between & 8.21 & 14 & 0.59 & 3.36 & 0.000 \\
& Within & 14.83 & 85 & 0.18 & & \\
& Total & 23.04 & 99 & & & 0.000 \\
H3a & Between & 106.42 & 14 & 7.60 & 8.04 & \\
& Within & 80.33 & 85 & 0.95 & & 0.000 \\
& Total & 186.75 & 99 & & & \\
\hline H3c & Between & 62.25 & 1 & 62.25 & 48.99 & \\
& Within & 124.51 & 98 & 1.279 & & \\
& Total & 186.75 & 99 & & & \\
& Between & 710.54 & 14 & 50.75 & 3.22 & \\
& Within & 1338.90 & 85 & 15.75 & & \\
& Total & 2049.44 & 99 & & & \\
\hline H4c & Between & 325.82 & 1 & 325.82 & 18.525 & \\
& Within & 1723.62 & 98 & 17.59 & & \\
& Total & 2049.44 & 99 & & & \\
\hline
\end{tabular}




\section{Page 31 of 40} Journal of Consumer Marketing

1
2
3
4
5
6
7
8
9
10
11
12
13
14
15
16
17
18
19
20
21
22
23
24
25
26
27
28
29
30
31
32
33
34
35
36
37
38
39
40
41
42
43
44
45
46
47
48
49
50
51
52
53
54
55
56
57
58
59

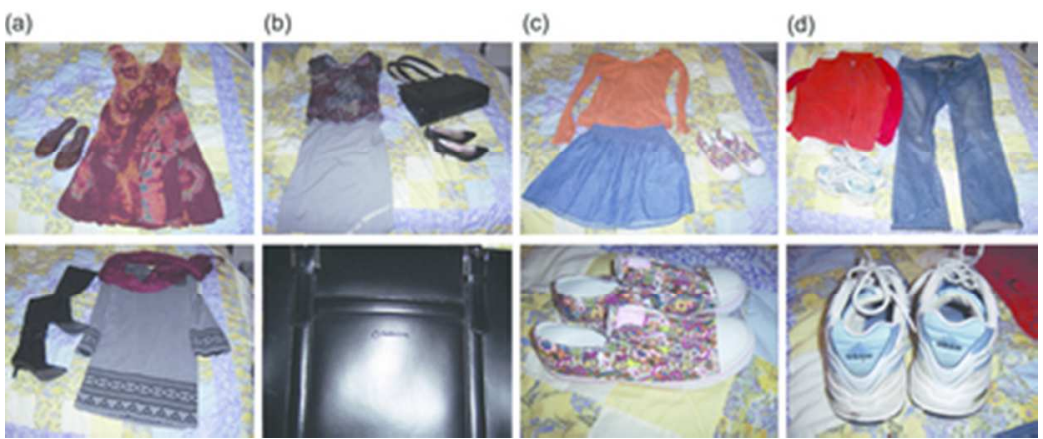

Brand visibility presence examples. Figure 1

$67 \times 27 \mathrm{~mm}(150 \times 150 \mathrm{DPI})$
2

4

5

7

8

10

12

13

16

17

19

20

21

23

24

25

26

27

28

30

31

32

33

34

35

36

37

38

39

40

41

42

43

44

47

48

49

50

51

52

55

56

57

58

59

60 
(a)
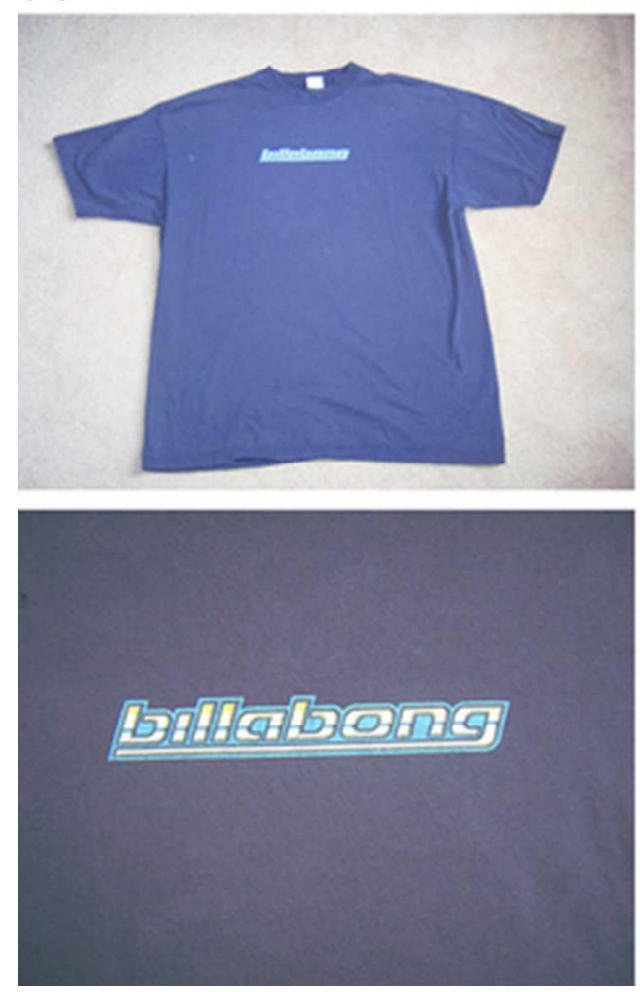

(b)
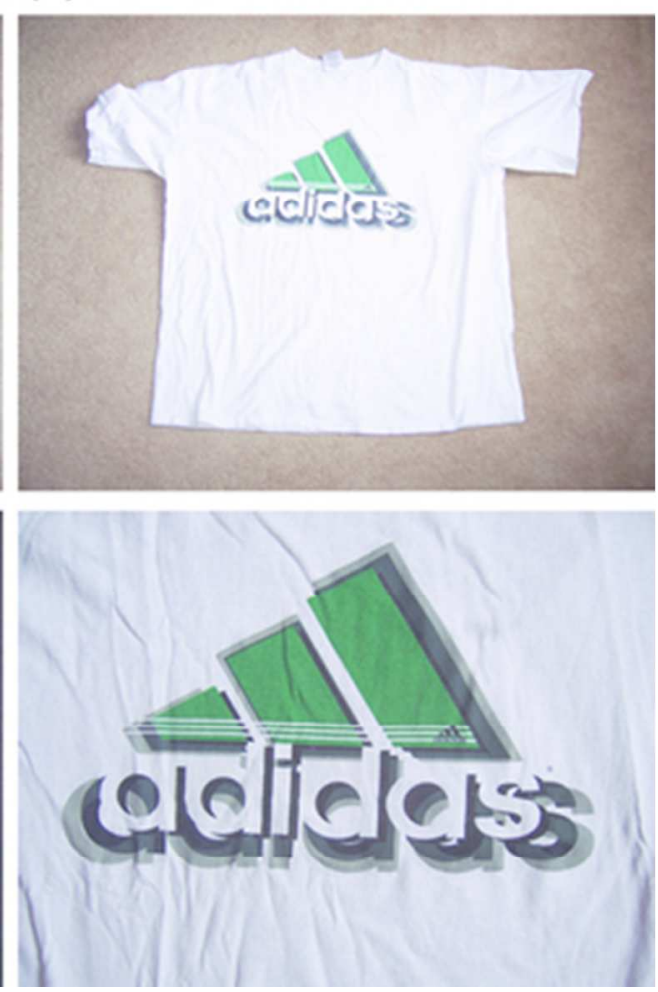

Brand visibility size examples.

Figure 2

$82 \times 68 \mathrm{~mm}(150 \times 150$ DPI $)$ 


\section{Page 33 of 40} Journal of Consumer Marketing

1

2

3

4

5

6

7

8

9

10

11

12

13

14

15

16

17

18

19

20

21

22

23

24

25

26

27

28

29

30

31

32

33

34

35

36

37

38

39

40

41

42

43

44

45

46

47

48

49

50

51

52

53

54

55

56

57

58

59

60 (a)

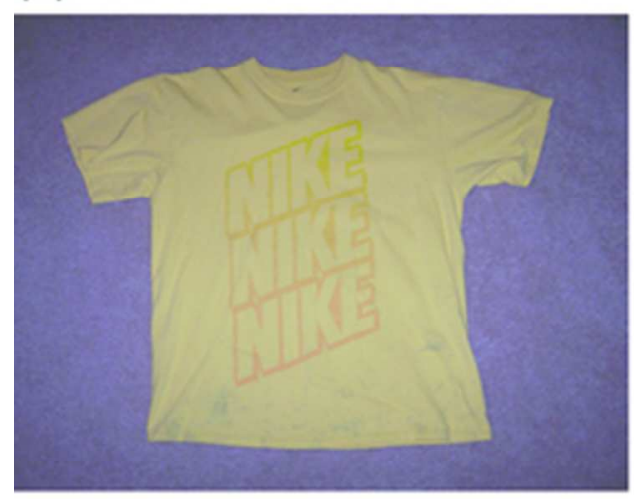

(b)

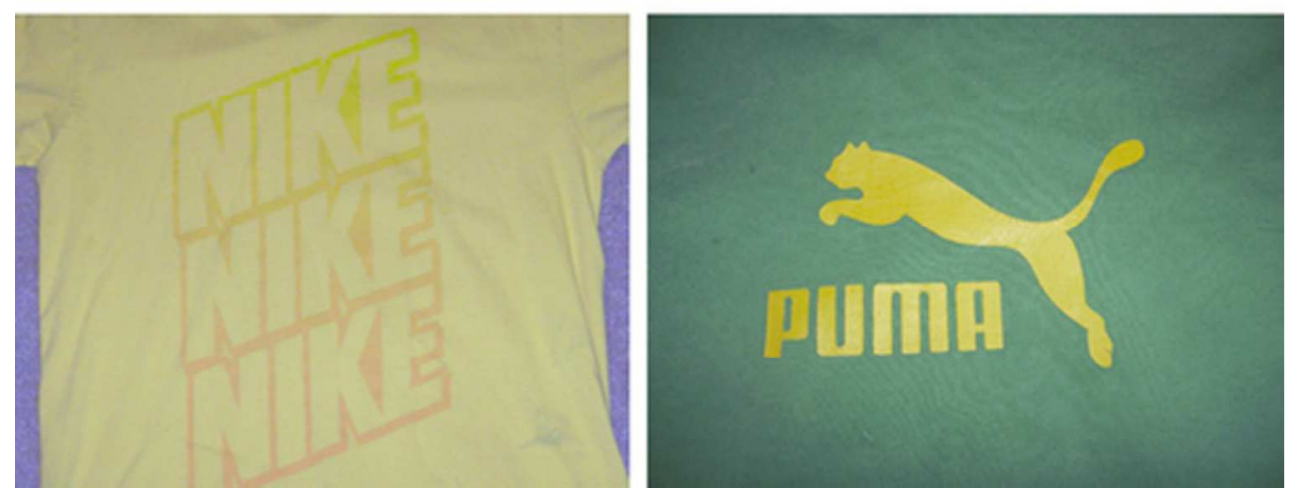

Brand visibility clarity examples.

Figure 3

$82 \times 68 \mathrm{~mm}(150 \times 150$ DPI $)$ 
(a)
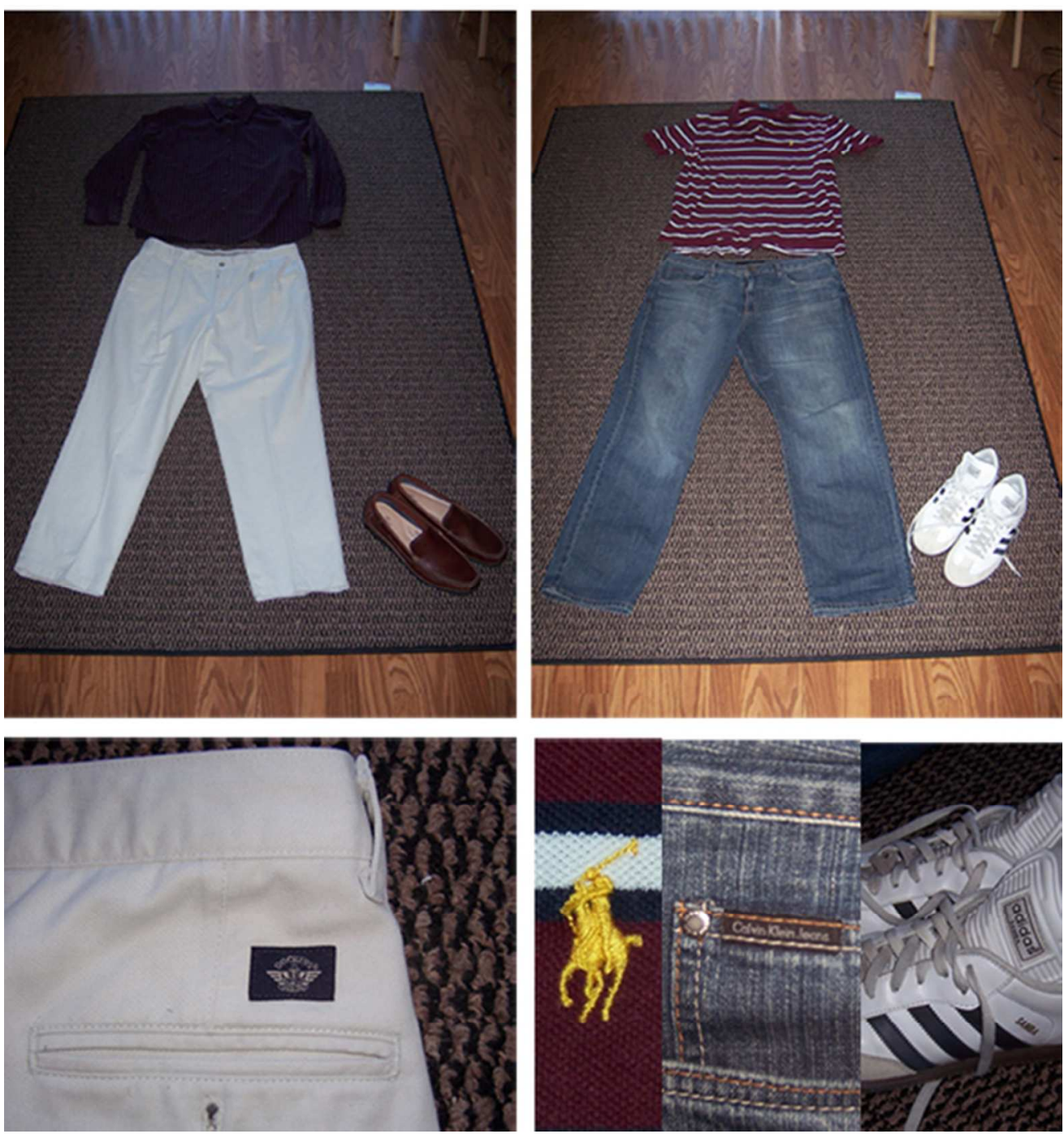

Individual unique brand frequency examples.

Figure 4

$113 \times 128 \mathrm{~mm}(150 \times 150 \mathrm{DPI})$ (b)

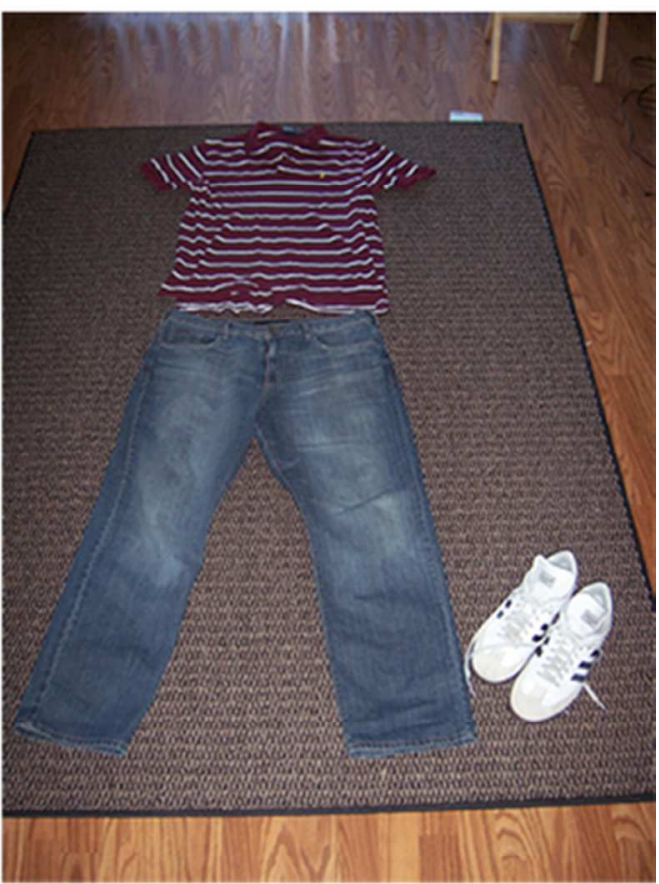


(a)
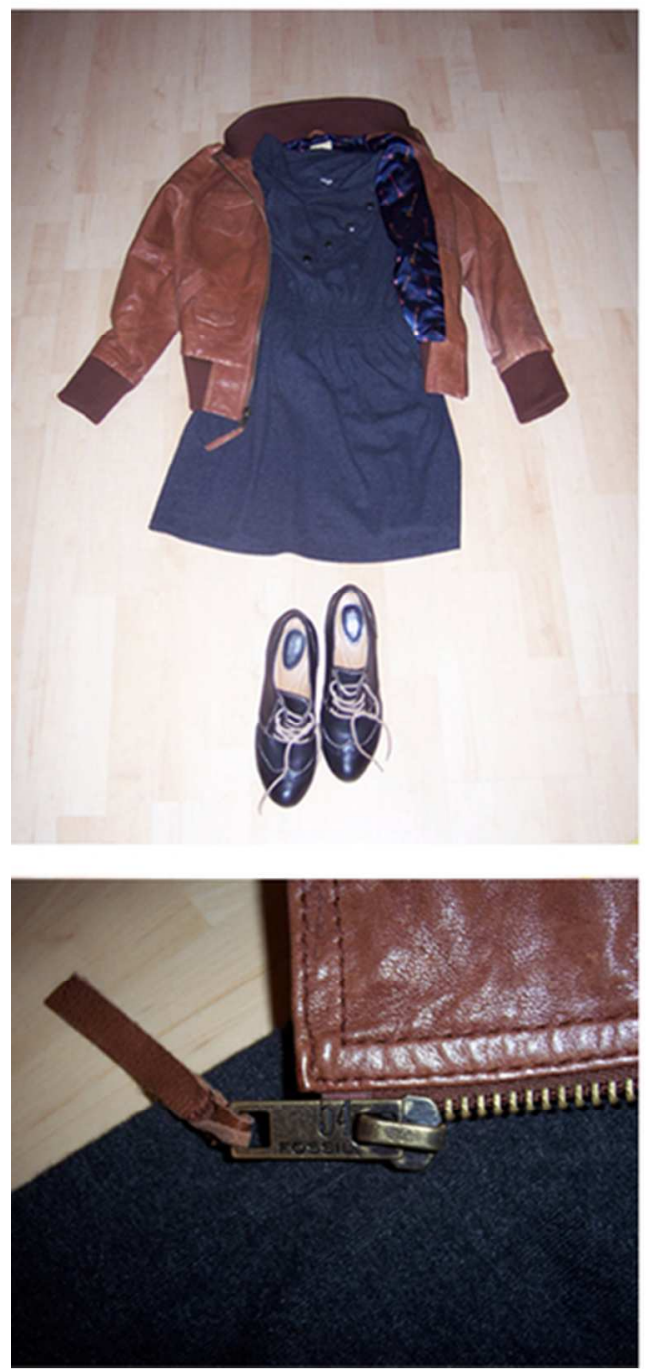

(b)
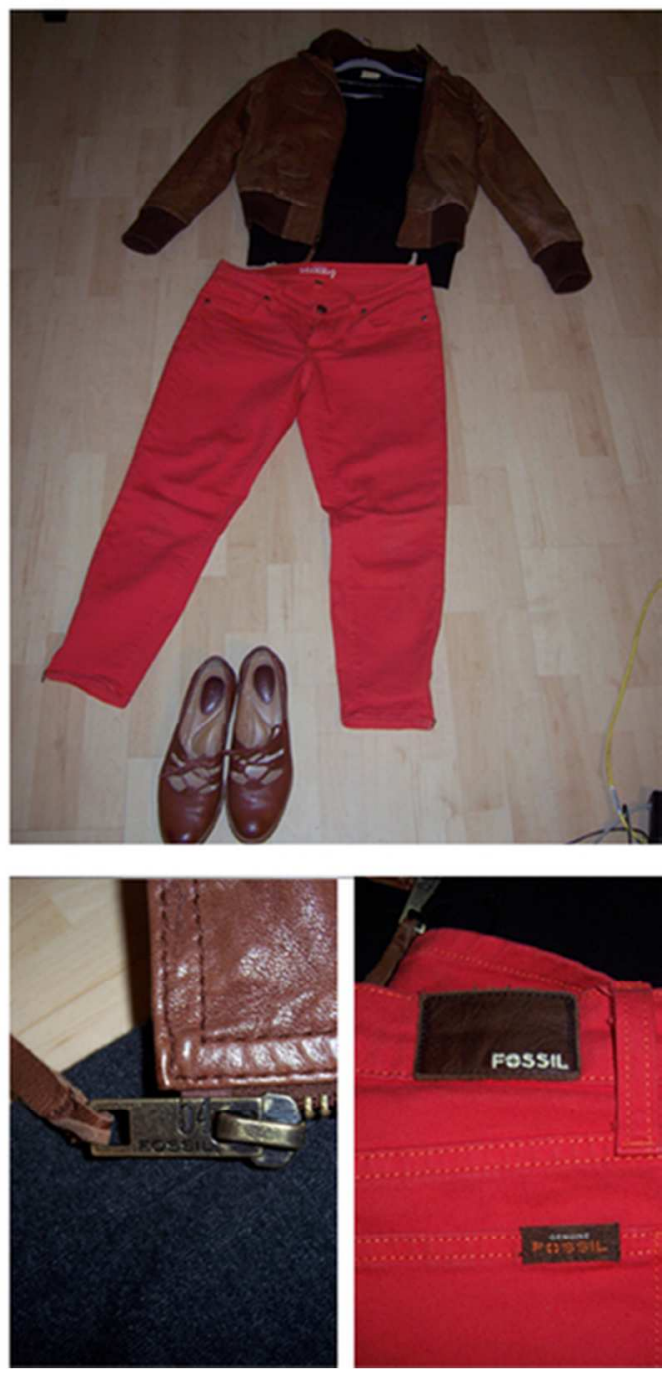

Individual gross brand frequency examples.

Figure 5

$108 \times 118 \mathrm{~mm}(150 \times 150 \mathrm{DPI})$ 
(a)
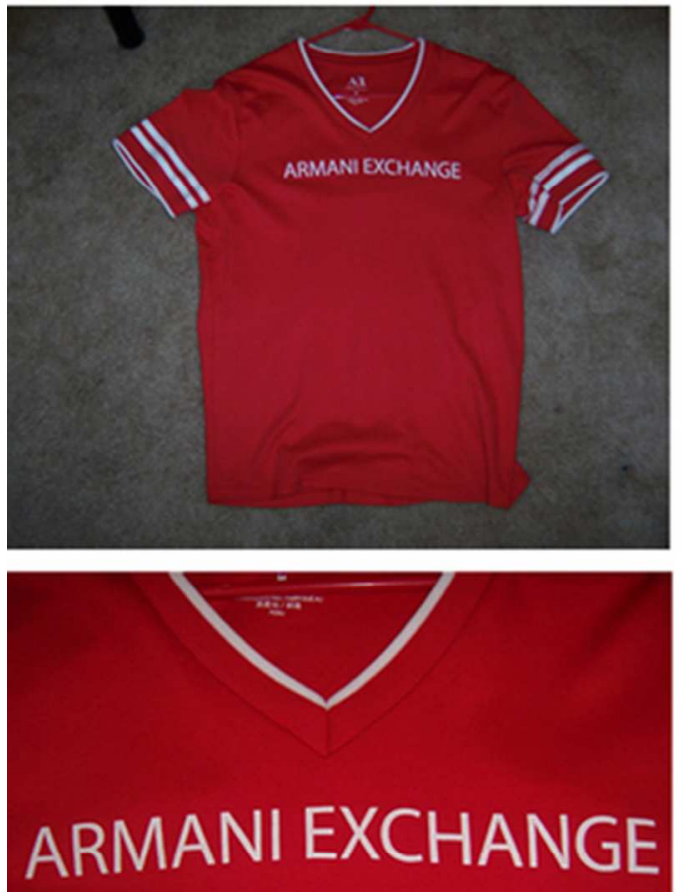

ARMANI EXCHANGE

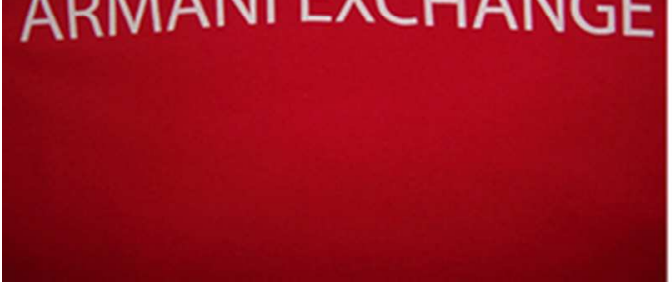

(b)
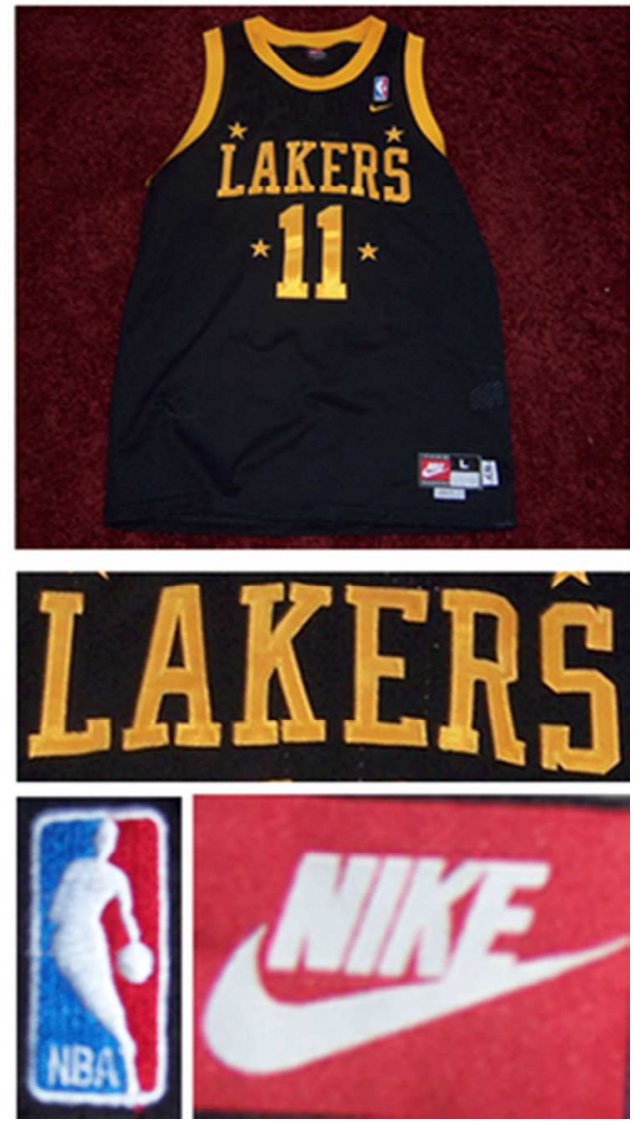

Product unique brand frequency examples.

Figure 6

$91 \times 84 \mathrm{~mm}(150 \times 150 \mathrm{DPI})$ 
(a)
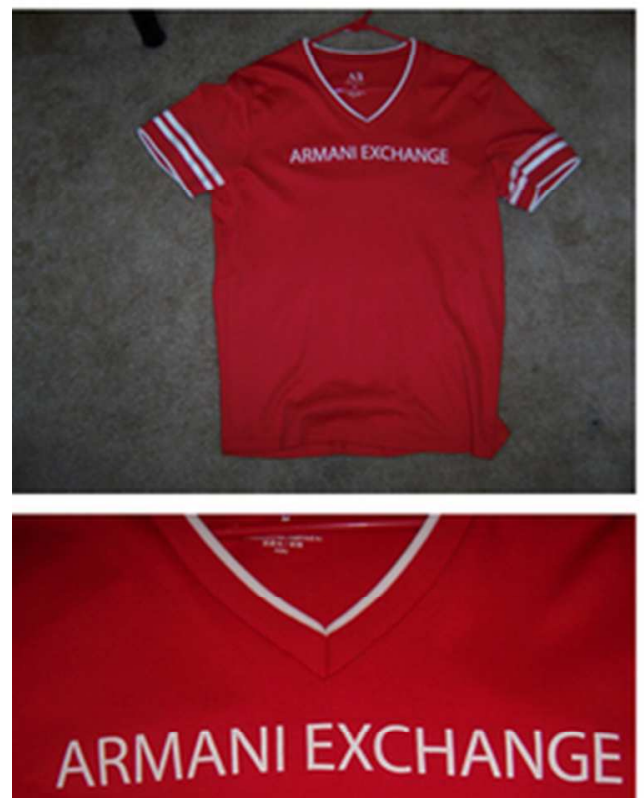

ARMANI EXCHANGE

(b)
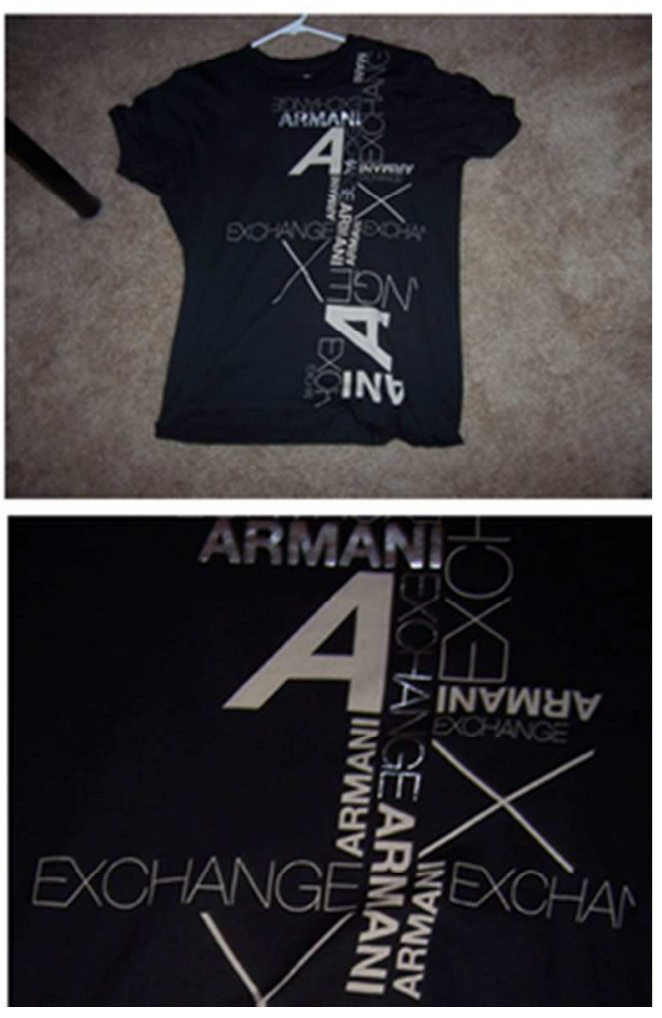

Product gross brand frequency examples.

Figure 7

$83 \times 70 \mathrm{~mm}(150 \times 150 \mathrm{DPI})$ 

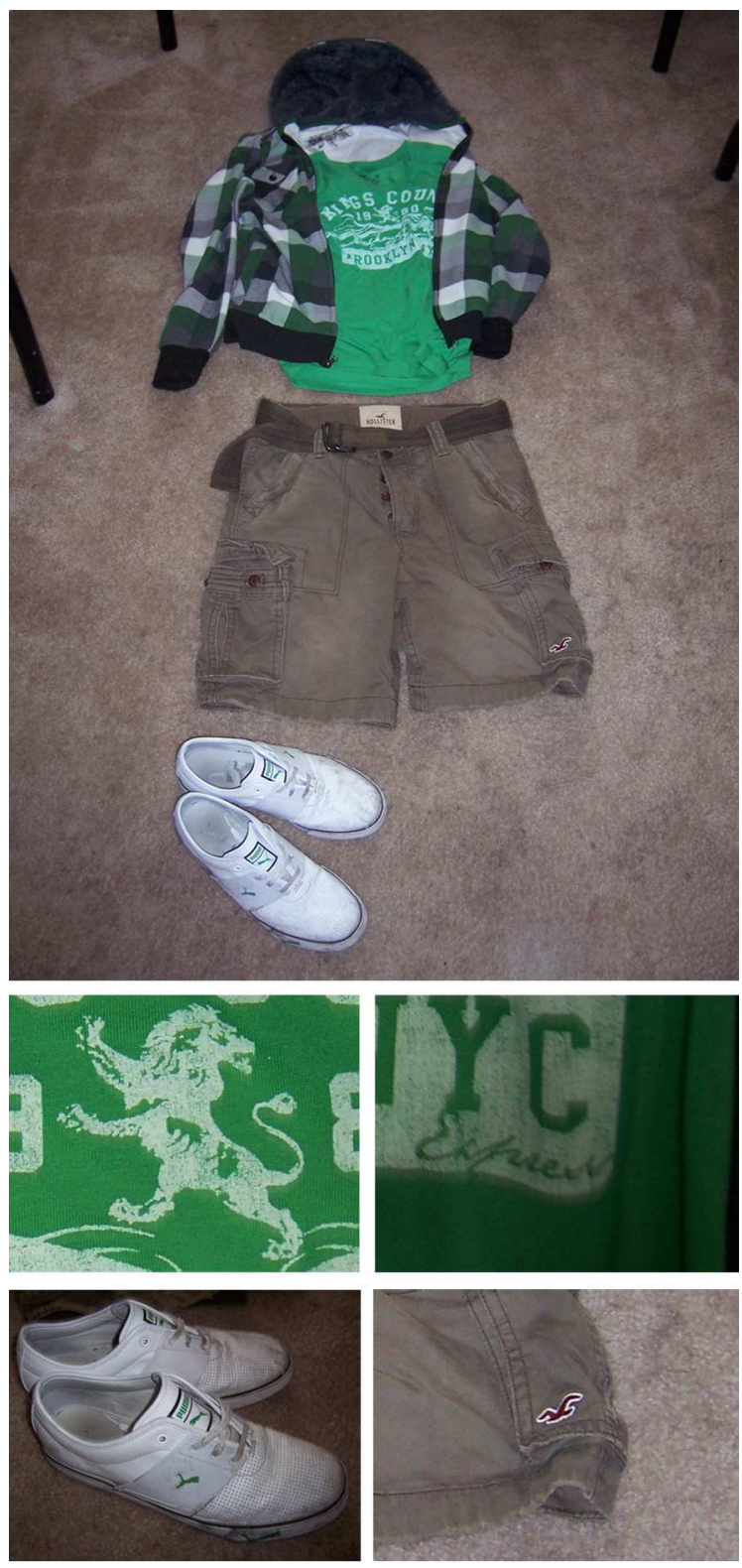

Individual distribution examples.

Figure 8

$212 \times 451 \mathrm{~mm}(150 \times 150 \mathrm{DPI})$ 


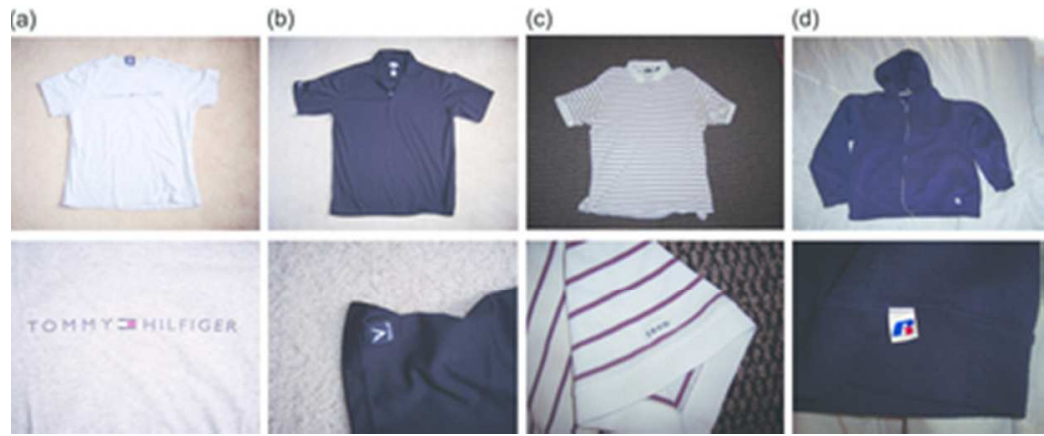

Product distribution examples.

Figure 9

$67 \times 27 \mathrm{~mm}(150 \times 150 \mathrm{DPI})$ 


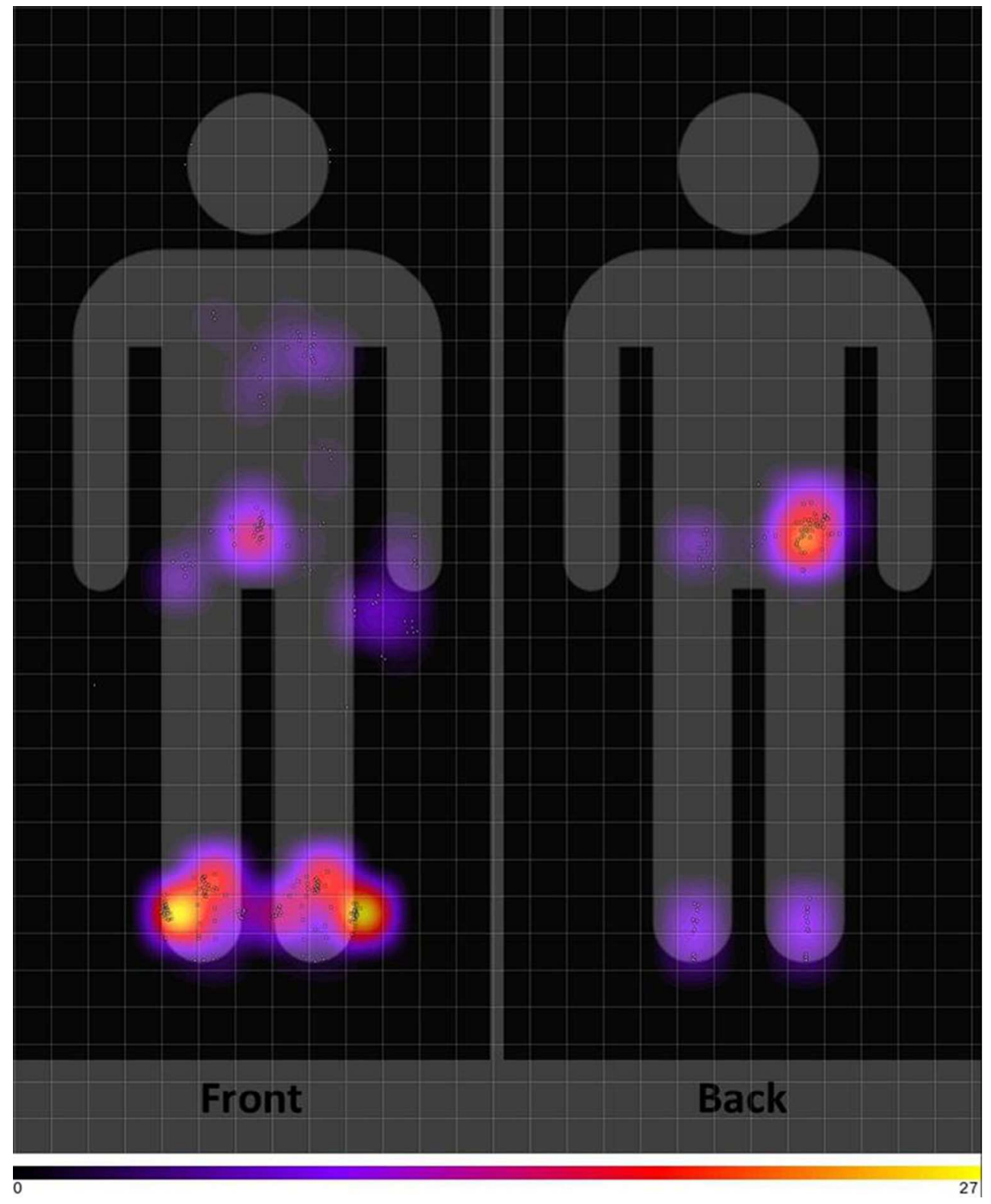

Heat map individual distribution results.

Figure 10

$179 \times 219 \mathrm{~mm}(150 \times 150 \mathrm{DPI})$ 